\title{
KREDIBILITAS PRIBADI GEMBALA DALAM PERTUMBUHAN GEREJA
}

\author{
JOHANNES RAJAGUKGUK
}

\begin{abstract}
Abstrak
Gembala sebagai pemimpin gereja merupakan salah satu penentu dari perkembangan gereja yang dipimpinnya. Mau tidak mau, seorang pemimpin gereja harus memiliki, menjaga dan meningkatkan kredibilitas (kualitas) pribadinya dari waktu ke waktu. Kredibilitas pribadi seorang pemimpin seharusnya akan memberi nilai tinggi bagi setiap pemimpin dimata mereka yang dipimpin dan mereka yang ada disekitar kelompok yang dipimpinnya. Kredibilitas pribadi seorang gembala yang mumpuni seharusnya akan mampu mengembangkan organisasi gereja yang dipimpinnya. Untuk dapat mengatakan bahwa seorang pemimpin atau gembala memiliki kredibilitas tinggi harus dilihat dari berbagai faktor, misalnya kepribadiannya, kemampuan komunikasinya, hubungan sosialnya, kompetensinya dan lain-lain.
\end{abstract}

Kata Kunci : kredibilitas, gembala , pemimpin, pertumbuhan gereja, indikator kredibilitas

\begin{abstract}
Abstrak
Shepherd as church leader is one of the determinants of the development of the church he leads. Inevitably, a church leader must possess, maintain and enhance his personal credibility (quality) from time to time. The personal credibility of a leader should give high marks to every leader in the eyes of those who are led and those around the group they lead. The personal credibility of a qualified shepherd should be able to develop the church organization he leads. To be able to say that a leader or pastor has high credibility must be seen from a variety of factors, such as his personality, communication skills, social relationships, competence and others.
\end{abstract}

Keywords: credibility, pastor, leader, church growth, credibility indicator

\section{PENGANTAR}

Seorang pemimpin baru akan diakui posisinya ketika memiliki kualitas tertentu dalam pemahaman akan tugasnya, akan kepercayaan diri dan visinya termasuk juga halnya gembala. Seorang pemimpin gereja tidak cukup hanya mengaku di-pimpin Roh Kudus saja, walaupun tidak perlu diragukan bahwa pemim-pin gereja mutlak dipimpin oleh Roh Kudus, tetapi menurut penulis, sebenarnya justru Roh Kudus bekerja juga melalui suatu kompetensi dasar, yang Allah sendiri telah bangun dalam diri manusia berupa kredi-bilitas ; Efesus 2:10 : Karena kita ini buatan Allah, diciptakan dalam Kristus Yesus untuk melakukan pe-kerjaan baik, yang dipersiapkan Allah sebelumnya. Ia mau, supaya kita hidup di dalamnya. Artinya, hadirnya sebuah kredibilitas merupakan juga bukti seseorang di-pimpin Roh Kudus untuk me-megang kepemimpinan di gereja

\footnotetext{
${ }^{1}$ Rick Meyers, STRONG Dictionary E-

${ }^{1}$ Rick Meyers,
SWORD Bible, $2000-2016$
}

\section{LANDASAN ALKITAB TEN-TANG KREDIBILITAS}

\section{Landasan Perjanjian Lama}

Kredibilitas adalah karya Roh Kudus. Roh Kudus mengurapi dan memberdayakan orang-orang pilih-anNya sehingga memiliki kemam-puan yang diperlukan untuk melak-sanakan rencana Tuhan. Be-zaleel dan Aholiab dipenuhi oleh Roh Kudus. Kata dipenuhi berasal dari kata Ibrani ợ mâlê', mâlâ' ${ }^{1}$ Yang dapat berarti diisi oleh, dikonfirmasi, berhasil karena, men-capai akhir oleh, mengalir, dipuas-kan, dikuasai sepenuhnya. Roh Kudus memenuhi seseorang dan hasil karyanya menjadi konfirmasi dari pekerjaan Roh Kudus. Roh Kudus membuat Bezaleel dan Aholiab memiliki kualitas yang diperlukan untuk kredibel sebagai pelaksana pem-bangunan tempat kudus. 
Jika orang tidak percaya dengan sang pembawa pesan, mereka tidak akan percaya kepada pesannya. Itu sebabnya, dalam Keluaran 18:17-23, pemimpin yang dianjurkan oleh mertua Musa, Yitro, untuk mem-bantunya memimpin bangsa Israel, haruslah orang-orang yang mem-punyai kredibilitas. Matthew Henry dalam Commentary nya memberikan keterangan bahwa ada 4 (empat) karakteristik pemimpin menurut Yitro (ay. 21), (a) Orang-orang yang cakap. Orang yang cakap dalam bahasa Ibrani חַיל chayil, khah'-yil ;2 Yang artinya tentara, mampu, berpegang pada nilai, kuat, aktif, terlatih, terampil. Kata mampu, kuat dan terampil jelas merujuk kepada kompetensi. Sementara, kata aktif dan berpegang pada nilai jelas merujuk pada karakter. (b) Takut akan Tuhan. Kata "takut akan Tuhan" berasal dari bahasa Ibrani ירירא יםמֶלה y yare Elohim ; fearing; morally reverent: afraid, fear $(-f u l)^{3}$ yang berarti takut, berpatokan, atau mengacu kepada. Nilai ini bisa diajarkan dan dilatih menjadi kompetensi, hingga menjadi karakter. Dan bila nilai ini dipegang dengan tekun, akan menjadi penopang karis-ma, yang artinya menjadi kredibi-litas. (c) Dapat dipercaya. Kata "dapat dipercaya" diambil dari kata Ibrani אֶֶֶ 'emeth, eh'-met; ${ }^{4}$ yang dapat diartikan stabil, Nampak yakin, benar, dapat dipercaya, meyakinkan, setia, jujur. Nilai ini merujuk pada karakter. (d) Benci kepada penge-jaran suap. Diartikan dengan tidak ingin memperkaya diri dengan suap. Kata "suap" diambil dari kata Ibrani בֶָּ betsa, beh'-tsah ${ }^{5}$ Yang dapat diartikan membenci perampasan dengan kekerasan, pengambilan ke-untungan yang tidak benar, ke-inginan mengambil milik orang lain. Jelas ini merujuk pada karakter dan kredibilitas.

\section{Landasan Perjanjian Baru}

\footnotetext{
${ }^{2}$ Meyers, STRONG Dictionary E-SWORD Bible, $\mathrm{H} 2342$

${ }^{3}$ Meyers, E-SWORD Bible, H3372
}

Alkitab mencatat kualifikasi karakter kepemimpinan yang didaftar dari 1 Timotius 3:1-13 dan Titus 1:5-9 dimana ada sejumlah standar ke-dewasaan karakter yaitu : (a) Tidak dapat dituduh (1 Tim. 3:2; Tit. 1:7), karena memiliki cara hidup yang tertib dan takut akan Tuhan. (b) Suami dari satu istri (1 Tim.3:2; Tit. 1:7), menjadi pemimpin dan teladan yang benar dalam keluarga. (c) Dapat menahan diri (1 Tim. 3:2; Tit 1:8). Bukan orang yang pemarah, menimbang segala sesuatu yang akan diucapkan, sabar. (d) Bijaksana (1 Tim. 3:2). Berhati-hati dalam setiap tindakan, penuh roh hikmat dan pengenalan akan Tuhan. (e) Sopan (1 Tim. 3:2), menghormati orang yang lebih tua. Dalam 1 Timotius 3: $1-7$, Rasul Paulus dalam suratnya ini telah menetapkan beberapa per-syaratan untuk menjadi penilik jemaat (episkopos). Penilik Jemaat (episkopos) pada waktu itu adalah tuan rumah dari jemaat yang ber-ibadah di rumahnya, dan karena itu menjadi pengawas/penilik atas per-temuan jemaat di sana (jabatan ini berkembang menjadi penatua seperti yang ada pada gereja masa kini). Ada sebab mengapa Paulus perlu me-netapkan persyaratan untuk menjadi penilik/pengawas. Orang yang Tuhan tetapkan dalam sebuah posisi perlu memiliki standart yang tinggi. Hal ini karena rasul Paulus melihat jabatan penilik/pengawas itu sebagai pekerjaan yang indah (KJV "good work"). Kualitas yang dimaksud bukan hanya sekedar kualitas dalam arti banyak tahu tentang sesuatu, tetapi kualitas dalam karakter.

Beberapa hal mengenai kredi-bilitas dicatat dalam perjanjian baru. Dalam Lukas 16:10 "Barangsiapa setia dalam perkaraperkara kecil, ia setia juga dalam perkaraperkara besar. Dan barangsiapa tidak benar dalam perkara-perkara kecil, ia tidak benar juga dalam perkara-perkara besar". Ketekunan untuk bertahan dalam proses dan memperhatikan hal-hal kecil akan

\footnotetext{
${ }^{4}$ Meyers, E-SWORD Bible, H539

${ }^{5}$ Meyers, E-SWORD Bible, H1214
} 
membawa pada perkara-perkara yang besar. Ke-tekunan akan membentuk karakter para pemimpin Kristen menjadi seperti Kristus dan menghasilkan buahbuah Roh. Pemimpin kristen dengan karakter Kristus, kredibi-litasnya pasti akan diakui. Kemudian dalam Lukas 14:31 "Atau, raja manakah yang kalau mau pergi berperang melawan raja lain tidak duduk dahulu untuk memper-timbangkan, apakah dengan sepuluh ribu orang ia sanggup menghadapi lawan yang mendatanginya dengan dua puluh ribu orang? (Luk. 14:31). Ini bicara tentang merencanakan sesuatu, menyusun strategi dan keahlian. Penulis menyebut ini se-bagai kompetensi.

Matius 9:17a "Begitu pula anggur yang baru tidak diisikan ke dalam kantong kulit yang tua, karena jika demikian kantong itu akan koyak sehingga anggur itu terbuang dan kantong itupun hancur". Untuk satu tanggung jawab baru perlu ada yang dirubah. Gembala dengan 100 jemaat dan gembala dengan 200 jemaat cara menanganinya pasti tidak sama. Tanggung jawab yang besar perlu perubahan kirbat. Pe-mimpin kristen perlu masuk proses agar berubah dalam hal karakternya dan perubahan itu menjadi kredibel untuk kepemimpinannya. Efesus 1:4 "Sebab didalam Dia Allah telah memilih kita sebelum dunia di-jadikan, supaya kita kudus dan tak bercacat dihadapanNya." Karena se-tiap pemimpin Kristen telah dipilih sejak sebelum dunia ada, maka setiap proses, pengalaman, peristiwa yang akan membentuk pemimpin Kristen, Tuhan sudah siapkan juga sebelum dunia ada. Setiap peristiwa hidup para pemimpin Kristen sudah di-siapkan untuk alasan dan tujuan tertentu. Kredibilitas adalah bukti seseorang dipimpin Roh Kudus dan itu perlu dibangun, disiapkan melalui se-tiap peristiwa hidup

\section{PENGERTIAN GEMBALA}

KREDIBILITAS

Kredibilitas dalam bahasa Inggris Credibility, menurut The Random House : Credibility (Eng-lish) [kred-uh-bil-itee]noun The quality of being believable or worthy of trust. ${ }^{6}$ Artinya, kredibilitas adalah kualitas yang dimiliki karena bisa dipercaya atau layak untuk diberi kepercayaan. Menurut Kouzer dan Posner, kredibilitas adalah mengenai bagaimana seorang pemimpin men-dapatkan kepercayaan dan keyakinan dari pengikutnya. Kredibilitas adalah mengenai apa yang dituntut pengikut dari pemimpinnya sebagai prasyarat agar mereka secara suka rela mem-berikan hati dan pikiran mereka dan kredibilitas juga mengenai tindakantindakan yang diambil para pe-mimpin untuk meningkatkan komit-men dari para pengikutnya. Apa yang dituntut dari pengikut terhadap pemimpinnya ini juga bicara tentang komponen-komponen kredibilitas di-dalam diri pemimpin tersebut. Be-berapa ahli menyampaikan unsur-unsur kredibilitas sebagai berikut :

Dari keseluruhan teori diatas, maka penulis menyimpulkan bahwa kredibilitas gembala adalah kualitas pribadi seorang gembala yang mem-buat ia bisa dipercaya atau diper-cayakan sebagai gembala. Kualitas pribadi itu dibentuk oleh ada tiga

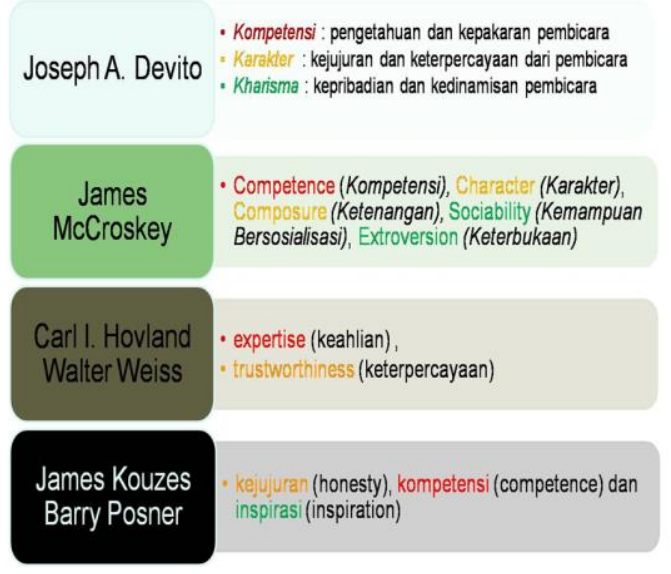

${ }^{6}$ Stephen Glazier, Random House Word Menu. (Toronto : Random House of Canada Limited, 1992), 614 
aspek utama kredibilitas yaitu kom-petensi,

\section{karakter dan karisma}

\section{Kompetensi}

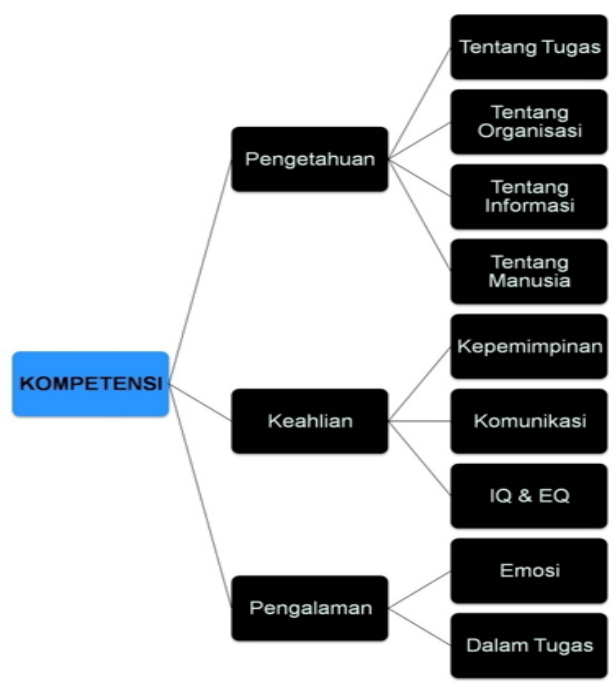

\section{a. Pengetahuan}

1) Pengetahuan tugas penggem-balaan

Istilah Gembala dalam ba-hasa Inggris Shepherd berarti domba sedangkan Ibrani kuno ra'ah artinya memberi makan sehingga Gembala dikenal sebagai orang yang mem-beri makan dan dapat ditujukan ke-pada individu yang membantu atau memelihara orang lain dimana se-seorang yang memperlihatkan ke-pedulian yang penuh kasih sayang. Sementara itu kata gembala dalam bahasa Latin ialah "pastor", dan dalam bahasa Yunani "poimen". Oleh sebab itu penggembalaan dapat juga disebut "poimenika" atau "pastoralia". "Pelayanan pastoral" adalah sebutan untuk penggembala-an. ${ }^{7}$

Tugas gembala dalam pe-ngertian asal katanya berarti orang-orang yang memberi makan yang membantu dan memelihara orang lain dengan penuh kasih sayang. Tugas-tugas penggembalaan ini di-

\footnotetext{
${ }^{7}$ Maria Bons-Storm,Apakah Penggembalaan Itu?(Jakarta : BPK Gunung Mulia, 2004), 4

${ }^{8}$ Dick Iverson,Building Churches That Last. (Oregon: City Bible Publishing. 2008), 56

${ }^{9}$ Munthe, Tema-Tema Perjanjian Baru. (Jakarta : BPK Gunung Mulia, 2006), 21
}

sebut juga pelayanan pastoral. Tugas seorang gembala, selain memberi makan, memelihara dan mengawasi, mereka juga adalah pelayan domba-dombanya. Penjelasan mengenai me-layani dombadomba dijelaskan oleh oleh Dick Iverson bahwa kompetensi gembala sejati itu pasti akan mem-beri makan, menuntun, memimpin dan mengarahkan dombadomba. ${ }^{8}$ Gembala mengasihi, peduli dan memberi hidup bagi domba-domba-nya, mengayomi kawanan domba di masa yang sulit. Ini adalah karakter gembala sejati.

Kawanan domba yang mengikuti gembala, memperlihatkan sebuah karisma yang dimiliki oleh gembala tersebut. Kemudian Munthe menambahkan tugas seorang gembala adalah pelayan bagi domba-dombanya seperti yang dsebutkan dalam 1 petrus 5:3 "Gembalakanlah kawanan domba Allah... janganlah kamu berbuat seolah-seolah kamu mau memerintah atas mereka, tetapi hendaklah menjadi teladan bagi kawanan domba itu." 9

Selanjutnya sebagai model atau panutan, seorang gembala diharap-kan dapat memotivasi dan memberikan pengaruh yang men-dukung pertumbuhan domba-domba-nya. Usaha untuk memberi pengaruh adalah bagian dari karisma seorang gembala untuk membawa umat gembalaannya bertumbuh.

\section{2) Pengetahuan tentang Organisasi}

Gereja adalah sebuah organi-sasi yang khas. Gereja ada atas ini-siatif Allah. Oleh karena itu gereja adalah milik Allah. Dalam pem-bangunan jemaat, gereja dihayati sebagai organisme dan organisasi. Sebagai organisme, gereja terus hidup, bertumbuh dan berbuah. ${ }^{10}$ Gembala sebagai

\footnotetext{
${ }^{10}$ Rijnardus A. van Kooji, et.al., Menguak Fakta, Menata Karya Nyata: Sumbangan Teologi Praktis dalam Pencarian Model Pembangunan Jemaat Konstekstual (Jakarta : BPK Gunung Mulia, 2007), 6
} 
pemimpin dalam gereja memiliki peran penting untuk membawa gereja terus hidup, bertumbuh dan berbuah. Dalam proses pertumbuhannya, seperti layaknya sebuah organisasi, gereja juga membutuhkan anggota, tempat, struktur, pembagian kerja, teknik pengorganisasian, lingkungan tertentu dan tujuan. Sebagai pemimpin dalam gereja, gembala juga membagi dan mengarahkan anggota jemaatnya kepada tujuan yang akan dicapai. Dimulai dengan sebuah visi ke-mudian merumuskannya menjadi sebuah aplikasi praktis yang dapat dijangkau semua anggota gereja. Karena itu gembala harus memiliki sebuah visi yang jelas dan terarah. Selain visi yang jelas, gembala juga menjadi pencipta iklim serta budaya kerja dalam gereja yang dipimpinnya. Kouzes dan Posner menyampai-kan bagaimana menjadikan setiap orang penting dalam sebuah organisasi, adalah bukti dari kredi-bilitas seorang pemimpin. Proses penguatan kredibilitas seorang gembala dimulai dengan mengklarifikasi nilainilai dan kepercayan yang dimilikinya, namun dengan ber-orientasi kepada pengikutnya ; dengan menghargai, menyerap aspirasi mereka, memberi perhatian serta menganggap masukan serta ide mereka penting maka gembala akan mendapatkan kepercayaan peng-ikutnya dengan demikian makin kuat pondasi kredibilitas dari gembala dan organisasi gereja yang dipimpinnya. ${ }^{11}$

\section{3) Pengetahuan tentang data dan informasi sumber daya}

Gembala gereja tentu saja perlu mendata timnya dan mengenali karunia yang dimiliki setiap anggota timnya sehingga dapat membuat rincian tugas yang sesuai dengan karunia dan potensi yang dimiliki anggota timnya. Para pemimpin dalam hal ini gembala juga mulai mendata

${ }^{11}$ James M Kouzes dan Barry Z. Posner. Credibility: How Leaders Gain and Lose it, Why People Demand it..(San Fransisco : Josey-Bass, 2011) 64 setiap sumber daya yang dimiliki dalam gereja serta me-ngelolanya seperti keuangan, per-lengkapan-perlengkapan ibadah yang dimiliki dan tentu saja manusia yang ada didalam organisasi gerejanya

Dalam pengelolaan informasi sangat penting bagi gembala untuk selalu mendistribusikannya. Seperti yang disampaikan Kouzes dan Posner, "Sharing information is es-sential to developing people's capa-city and to building and sustaining credibility. When there's a high deg-ree of transparency and when information is easily available and accessible, people come to trust their leaders, their team members and their organization." 12

Gembala yang selalu berbagi informasi sangat penting untuk mengembangkan kapasitas orang-orang yang dipimpinnya dan untuk membangun dan mempertahankan kredibilitas. Bila ada transparansi yang tinggi dan bila informasi mudah didapat dan mudah diakses, orang percaya pada pemimpin mereka, anggota tim dan organisasinya.

\section{4) Pengetahuan tentang manusia}

Para pemimpin yang hebat harus memiliki keahlian tentang manusia. Mereka harus mampu ber-hubungan dengan orang-orang dari berbagai kalangan, kepada orang-orang dengan kepribadian yang unik, masalah kekuasaan dan kurangnya harga diri. ${ }^{13}$ Selain itu juga dalam hal berhubungan dengan orang-orang, Alkitab mengamanatkan bahwa gem-bala sebagai pemimpin rohani me-miliki dan memperlihatkan buah Roh (Gal. 5:22) serta sikap mengasihi, peduli dan mau membantu memikul beban orang lain (Fil.2:1-4). Jadi kemampuan mereka mengadakan hubungan sebagai pemimpin adalah pemberian Allah dan diberi kuasa oleh Roh.

\footnotetext{
${ }^{12}$ Kouzes \& Posner, Credibility. 125

${ }^{13}$ Bill Hybels, Kepemimpinan yang Berani. (Batam : Gospel Press, 2004), 155
} 
14 Bill Hybels menyampai-kan keahlian tentang manusia mencakup kepekaan terhadap pe-mikiran dan perasaan orang lain dan kemampuan mendengarkan.

\section{b. Keahlian}

\section{1) Kepemimpinan}

George Barna menjelaskan arti kepemimpinan "leadership is the process of motivating, mobilizing, resourcing and directing people to passionately and strategically pursue a vision from God that a group jointly embraces."15 Kepemimpinan adalah proses memotivasi, meng-gerakkan, mengembangkan potensi, mengarahkan orang-orang dengan penuh semangat dan secara strategis mengejar visi dari Tuhan bersama-sama dalam satu kelompok. Hal utama dari kepemimpinan seorang gembala cabang, ia harus memiliki visi terlebih dulu. Amsal 29 : 18a berkata "Jika tidak ada wahyu, maka liarlah rakyat." Kata liar menunju-kan ketidak teraturan dan ketidak-hadiran kepemimpinan.

Kouzes dan posner dalam riset mereka mengenai kepemim-pinan yang efektif menyampaikan, "Leadership is a relationship bet-ween those who aspire to lead and those who chose to follow. Sometimes the relationship is oneto-many. Sometimes it's one-to-one. But regardless of whether the number is one or one thousand, leadership is a relationship."16 Kepemimpinan merupakan hubungan antara mereka yang terpanggil untuk memimpin dan mereka yang memilih untuk mengikuti. Kadangkadang hubung-an itu antara satu dan banyak orang, kadang juga hubungan orang per orang. Tapi tidak peduli mau satu atau seribu, intinya kepemimpinan adalah sebuah hubungan Hubungan baik dengan

\footnotetext{
${ }^{14}$ George Barna, Leaders on Leadership : Pandangan Para Pemimpin Tentang Kepemimpinan.(Malang : Gandum Mas, 2009)

${ }^{15}$ George Barna, A Fish Out of Water, (Nashville: Integrity Publisher 2002), 7
}

orang lain harus dimulai oleh gembala cabang sebagai pe-mimpin. Ia harus memiliki tekad untuk menyukainya, menghidupinya dengan melaksanakannya dengan penuh tanggung jawab. Prinsip kepemimpinan Tuhan Yesus tetap berlaku di sini, yaitu: "Segala sesuatu yang kamu kehendaki supaya orang perbuat kepadamu, perbuatlah demikian juga kepada mereka" (Matius 7:12). Seorang pemimpin, dalam hal ini gembala cabang berhubungan dengan jemaat, bagai-mana memperlakukan jemaat dan berhubungan dengan jemaat. Mem-bangun sebuah hubungan dimulai dengan komunikasi. Inti dari semua kompetensi kepemimpinan yang hidup membutuhkan keterampilan berkomunikasi.

\section{2) Kemampuan Berkomunikasi}

Pat Williams mengatakan "Great leaders are great commu-nicator." 17 Pemimpin besar adalah juga komunikator yang hebat. Dengan kata lain bagaimana seorang pemimpin berkomunikasi menunjukan kualitas kepemimpinannya. Dalam katalognya tentang karunia rohani dalam 1 Korintus 12: 4-11 Paulus menyertakan karunia komu-nikasi (ayat 10). Dalam pelayanan Kristen, komunikasi melibatkan baik karunia pemberdayaan oleh Roh Allah dan seni dan teknologi dari simbolisme yang sesuai. Gembala dalam perannya sebagai seorang pembicara perlu memahami penting-nya sebuah proses komunikasi, mulai dari pemilihan katakata, serta simbol-simbol yang tepat sehingga yang disampaikan tepat sasaran. Dengan mengetahui cara ber-komunikasi yang baik, penginjilan menjadi lebih efektif. Seperti yang disampaikan

\footnotetext{
${ }^{16}$ James M. Kouzes dan Barry Z. Posner. The Leadership Challenge (Tantangan Kepemimpinan). Ed. Ketiga. Terj. Revyani Sjahrial.( Jakarta: Erlangga, 2004), 21

17 Pat Williams, Leadership Excel-lence. (Ohio : Barbour Publishing, 2012), 66
} 
sebelumnya oleh Jack Hayford, salah satu tugas peng-gembalaan adalah pemberitaan Injil dapat disampaikan dan penyebarannya dapat dilipatgandakan agar semua orang dapat mendengar pesan surga.

Kesimpulannya kemampuan berkomunikasi bukan hanya sekedar menyampaikan pesan. Tapi me-mahami bagaimana sebuah komu-nikasi dikemas sedemikan agar pesan injil dapat diterima secara efektif. Selain penyebaran pesan Injil, yang tidak kalah penting adalah bagaimana gembala menyampaikan pesan visi sehingga dipahami dan diterima semua anggota timnya. Penyampaian visi ini perlu diulang dari waktu ke waktu untuk mengkalibrasi setiap pemahaman dalam tim tentang visi gembala.

Gembala sebagai pemimpin gereja perlu mengerti apa yang men-jadi kerinduan dan ketakutan dari orang-orang yang dipimpinnya, apa yang menjadi kesukaan dan ke-sedihan mereka, dan memahami pengalaman hidup mereka seperti pernah mengalami pengalaman yang sama dengan mereka. Bill Hybels menyebut ini sebagai bentuk ke-ahlian manusia artinya cakap dalam hal kepekaan terhadap pemikiran dan perasaan orang lain dan kemampuan untuk mendengarkan, artinya sung-guh-sungguh mendengarkan. ${ }^{18}$ Jadi bukan hanya cakap dalam menyam-paikan sebuah visi atau pesan, tapi seorang gembala juga memiliki kemampuan mendengar.

\section{3) Intelligence Quotient dan Emotional Quotient}

Berdasarkan beberapa de-finisi tentang intelegensi disimpul-kan bahwa intelegensi adalah ke-mampuan yang dibawa sejak lahir yang dapat digunakan untuk me-nyesuaikan diri terhadap kebutuhan baru dengan menggunakan alatalat berpikir yang sesuai dengan tujuannya. Berdasarkan penelitian Goleman dikembangkan hipotesis bahwa untuk sukses ditempat kerja, yang diperlukan adalah sepertiga kemampuan IQ (Intellectual Intel-ligence) dan dua pertiga kemampuan EQ. Seberapa besar pengaruh EQ dalam kepemimpinan juga disampaikan Bill Hybels dalam bukunya Kepemimpinan yang Berani, yang mengomentari dari buku Emotional Intelligence :

"Sejak diterbitkannya buku itu, dimana Goleman telah meng-habiskan sebagian besar waktunya untuk menganalisa mengapa be-berapa persen pemimpin dapat ber-kembang hingga potensi mereka yang penuh, sedangkan kebanyakan pemimpin hanya berhasil mencapai kurang dari apa yang diharapkan dari mereka. Menurut Goleman, bentuk pengendalian diri ini diperlihatkan oleh para pemimpin saat mereka bertekun dalam kepemimpinan walaupun banyak mendapatkan per-lawanan atau merasa patah se-mangat; saat mereka menolak untuk menyerah pada masa-masa krisis; saat mereka berhasil mengendalikan ego mereka; dan saat mereka tetap fokus pada misi mereka dan bukannya terganggu oleh agenda orang lain. Goleman yakin bahwa para pemimpin yang menonjol berbeda karena mereka "sadar akan kekuatan mereka, batas-batas mereka dan kelemahan mereka." 19

Dari apa yang disampaikan Hybels, para pemimpin yang berhasil melewati tantangan kepemimpinan dan mencapai potensi kepemimpinan mereka dengan maksimal dipenga-ruhi oleh emotional intelligencenya. Dalam hal kepemimpinan gembala, tentu diperlukan kedua-duanya. IQ untuk mengorganisasi, membuat strategi, mendata sumber daya, menentukan perencanaan keuangan. Namun selain itu peran dari gembala yang utama adalah memberi nasehat dan pastoral konseling. Dalam hal inilah diperlukan kecerdasan emosi yang tentu saja berasal dari hikmat Tuhan tetapi juga perlu dikembangkan dan dilatih agar proses kon-seling 
tepat sasaran dan meng-hasilkan solusi atas masalah yang dihadapi jemaat.

\section{Karakter}

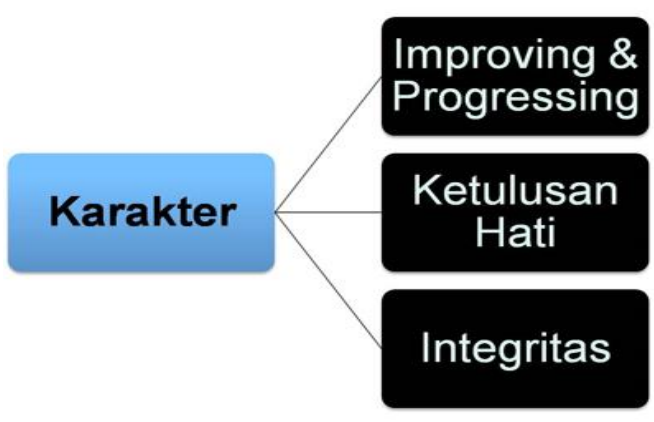

Unsur dari karakter adalah keterpercayaan. Seorang gembala harus bisa dipercaya, jujur, berkaitan dengan watak dan bermoral. Ke-terpercayaan itu berarti seorang gembala bersikap tulus tidak me-miliki motif tertentu. Gembala yang memiliki kemampuan menghargai, percaya dan mudah dipercaya dikatakan sebagai seorang yang memiliki kredibilitas pribadi. Agar pemimpin kredibel di mata pengikut-nya, selain ia harus dipercaya juga satu antara kata dan perbuatan, penulis menyebutnya sebagai in-tegritas. Kajian hermeneutika ten-tang ketulusan hati berbicara tentang integritas seorang pemimpin. Raja Daud dalam kitab suci dikatakan bahwa "Ia menggembalakan umat Israel dengan ketulusan hatinya, dan menuntun (memimpin) mereka dengan kecakapan tangannya" (Maz-mur 78:72). Itu sebabnya memiliki kompetensi dalam kepemimpinan saja tidak cukup, dibutuhkan juga ketulusan hati.

Myles Munroe menuliskan bahwa salah satu kualitas dan karak-teristik yang diperlukan dalam ke-pemimpinan sejati adalah Integritas yaitu konsistensi dalam perkataan dan tindakan seseorang; kelayakan untuk dipercaya; karakter yang benar. ${ }^{20}$ Dari dua pernyataan di atas, terlihat jelas bagaimana kepercayaan bisa dibangun ketika seseorang me-miliki integritas. Gembala yang ber-integritas, yang

${ }^{20}$ Myles Munroe, The Spirit of Leadership.(Jakarta : Immanuel, 2006), 276 konsisten dalam per-kataan dan tindakan adalah gembala yang dapat membangun rasa percaya orang-orang yang dipimpinnya.

George Barna dalam A Fish Out of Water memaparkan bahwa ada dua tipe pemimpin di dunia ini, yaitu pemimpin yang dilahirkan atau habitual leader dan pemimpin yang diajar atau situational leader. ${ }^{21}$ Menurut pandangan penulis, yang paling baik adalah pemimpin yang dilahirkan dengan bakat kepemim-pinan yang juga belajar dan diajar lewat suatu proses pematangan. Bicara tentang kredibilitas, memim-pin adalah bagian dari kompetensi yang perlu dikembangkan oleh gembala. Bagaimana seorang pe-mimpin membangun kredibilitas dipengaruhi oleh karakter warisan dari kedua orang tua kandungnya, tapi itu bukan satu-satunya faktor, ada faktor-faktor pembentuk diluar karakter warisan yaitu motivasi, temperamen, persepsi dan kehidupan sosial yang juga memberi pengaruh terhadap pembentukan kredibilitas seseorang. Kredibilitas ini yang akan menentukan keberhasilan kepemim-pinan seorang gembala.

\section{Karisma}

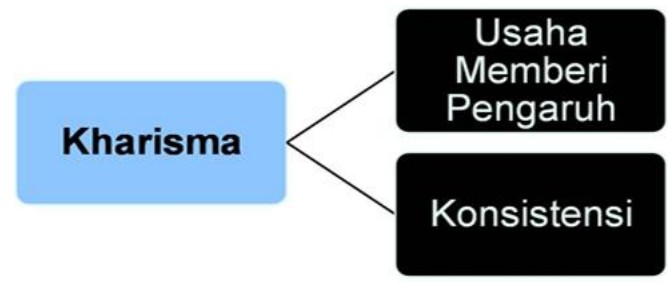

Pemimpin karismatik menarik para pengikut, mengilhami kesetiaan dan memobilisasi dukung-an. Tentu saja diperlukan sebuah pengaruh untuk dapat menarik peng-ikut dan memobilisasi dukungan. Banyak orang beranggapan

\footnotetext{
${ }^{21}$ Barna, A Fish Out of Water, 21
} 
bahwa karisma adalah anugerah. Beberapa orang memilikinya, yang lain tidak. Kata karisma itu sendiri benar-benar menguatkan pengertian ini, karena karisma berasal dari kata Charisma (Yunani)

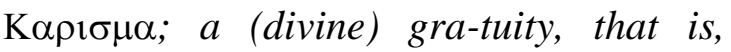
deliverance (from danger or passion); (specifically) a (spiritual) endowment, that is, (subjectively) religious qualification, or (objectively) miraculous faculty: - (free) gift. $^{22}$ yang dapat berarti pem-berian ilahi, dalam bentuk kelepasan, pemberian rohani, kualifikasi reli-gious atau mujizat dan pemberian cuma-cuma. Tapi Pat William me-negaskan bahwa walaupun penyebutannya disebut sebagai pemimpin karismatik, tetapi untuk menjadi pemimpin yang lebih berkarismatik tetap bisa dipelajari. Tahap-tahap pengaruh tidak muncul seketika, tetapi tumbuh secara bertahap.

Peter Drucker meneliti pe-mimpin yang luar biasa memiliki perbedaan karakter dan kecakapan yang sangat terlihat. Bagaimanapun mereka harus terus konsisten dan setia mempertahankan tindakan hingga tujuan tercapai. ${ }^{23}$ Membawa orang maju dan mempengaruhi mereka serta pengaruh tersebut dapat terus bertumbuh, diperlukan karakter yang konsisten dan setia serta penuh komitmen untuk mencapai tujuan tersebut. Penulis melihat Peter Druc-ker tidak seperti Pat Williams yang menghubungkan karisma dengan ke-tekunan melatih sebentuk keteram-pilan, justru menghubungkan karis-ma dengan ketekunan dalam mencapai tujuan. Penulis berpen-dapat, ketekunan dalam keteram-pilan, perlu sejalan dengan tujuan yang hendak dicapai dan dilakukan dengan konsisten. Serta, konsisten dalam memegang nilai-nilai moral yang menjadi pegangan seorang pemimpin atau gembala.

${ }^{22}$ Rick Meyers, STRONG Dictio-nary ESWORD Bible, 2000-2016

${ }^{23}$ Ted W. Engstrom, The Making of Christian Leader.(Michigan : Grand Rapids, 1980), 83

\section{Langkah-langkah pemimpin me- ningkatkan kredibilitas pribadinya}

\section{Mempertajam visi untuk me- ningkatkan kompetensi ke- pemimpinan}

Bill Hybels menuliskan pengembangan kepemimpinan me-nuntut sebuah visi. Menciptakan visi hanya sebuah permulaan, tantangan berikutnya adalah merancang strategi untuk mengubah sebuah visi menjadi kenyataan. ${ }^{24}$ Sebuah visi bisa dipastikan terwujud jika seorang pemimpin Kristen dalam hal ini gembala selain diurapi Roh Kudus tetapi juga dapat menerapkan praktek kepemimpinan terbaik dan bisa terus dilakukan dengan cara tidak pernah berhenti belajar. Pemimpin terbaik adalah pembelajar terbaik. Belajar adalah guru dari sebuah keahlian.

\section{Meningkatkan seluruh indi-kator kredibilitas dari waktu ke waktu}

Daniel Brown dan Brian Larson juga menyatakan kredibilitas seorang pemimpin Allah itu di-bangun dari waktu ke waktu. Ketika pemimpin, dalam hal ini gembala, menggali firman-Nya dan mulai membagikan dengan jemaat, dengan berjalannya waktu jemaat akan menilai "gembala kami tahu apa yang dibicarakannya". Semakin kre-dibel seorang pemimpin, semakin banyak yang akan datang meng-ikutinya. Dengan berlalunya waktu sambil terus tekun mencari tuntunan Tuhan akan membangun kredibilitas pemimpin dihadapan banyak orang.

\section{Membangun integritas yang teruji}

Salah satu bentuk integritas yang perlu terus dibangun seorang gembala

\footnotetext{
${ }^{24}$ Hybels, Kepemimpinan yang Berani, 149
} 
adalah integritas spiritual-nya, dari sinilah akan banyak mempengaruhi terhadap pertumbuh-an organisasi gereja serta orang-orang yang dia pimpin. Integritas spiritual adalah sesuatu yang dimiliki karena apa yang dilakukan dan katakan di mata Allah yang menguji hati seseorang "(1Tes 12: 4). Inilah yang menjaga gembala dari ke-inginan menyenangkan orang lain dan melayani diri sendiri. Disisi lain, kredibilitas spiritual muncul sebagai hasil dari apa yang gembala lakukan dan katakan di mata orang-orang ketika mengerjakan pekerjaan baik dan menyelesaikan dengan hasil yang excellent serta mendatangkan kebaikan bagi semua orang" (Titus 3: 8). Bila hubungan kita dengan Tuhan sunguhsungguh berdampak terhadap hubungan kita dengan orang lain, kita sedang membangun kredibilitas. Memimpin sesuai apa yang dikatakan dalam Alkitab di Yohanes 15:5 : “Akulah pokok anggur dan kamulah ranting-rantingnya. Barang-siapa tinggal di dalam Aku dan Aku di dalam dia, ia berbuah banyak, sebab di luar Aku kamu tidak dapat berbuat apa-apa.”

\section{Membangun orang-orang yang dipimpinnya}

Kepemimpinan sejati adalah proses membudidayakan pengaruh di masa depan orang-orang yang dipim-pinnya. Pengaruh tersebut terus ber-tumbuh dari waktu ke waktu secara berturut-turut dan berdampak positif bagi kehidupan orang lain. Setiap kali pengaruh itu berdampak, pada saat itulah pemimpin mendapatkan kredibilitasnya. Kredibilitas pemim-pin bertumbuh ketika orang per-orangan, setiap tim, departemen dan organisasi yang dipimpinnya mampu melakukan pekerjaan mereka dan menepati setiap janji ; bukan hanya sekedar meningkatkan reputasi saja.

\section{Hubungan antara kredibilitas gembala dengan pertumbuhan gereja}

Peter Wagner memberi defi-nisi mengenai pertumbuhan gereja secara operasional : "partumbuhan gereja meliputi segala sesuatu yang ada sangkut pautnya dalam usaha membawa orang-orang yang tidak mempunyai hubungan pribadi dengan Yesus Kristus kepada perse-kutuan denganNya dan kepada ke-anggotaan gereja yang bertanggung jawab." 25

George W. Peters dalam bukunya "A Theology of Church Growth", mengatakan beberapa ciri utama seorang hamba Allah yang hidupnya dapat dipakai Allah untuk mendatangkan pertumbuhan gereja-Nya :

Pertama, ia telah menerima panggilan Tuhan Yesus Kristus dan tetap setia mengikuti Tuhan dalam situasi apapun, terlepas dari kelemahan dan keterbatasannya, ia akan setia berkata sama seperti Petrus "Tuhan, kepada siapakah kami akan pergi"? (Yoh. 6:68).

Kedua, ia adalah hamba yang dengan sukarela memasuki pelayanan kepada Kristus dan gereja-Nya tanpa ambisi mencari kekayaan material dan kepentingan pribadi (Matius 26:57-62;14:2533).

Ketiga, ia adalah hamba yang mengalami persekutuan yang makin hari makin mendalam dengan Tuhan, sehingga ia bukan saja mampu menyampaikan FirmanNya, tetapi juga menjelaskan prinsip- prinsip yang diajarkan-Nya dan memancarkan Tuhan dari dirnya (I Petrus 2:9).

Keempat, ia adalah hamba Allah yang hidup dan berjalan di dalam Roh Allah (Galatia 5:25;Efesus 4:30).

Kelima, ia adalah hamba yang telah menetapkan prioritas hidup-Nya baik dalam kehidupan pribadi

${ }^{25}$ Peter Wagner, Gereja Saudara Dapat

Bertumbuh. (Malang : Gandum Mas, 2002). 54 
maupun dalam pelayanan (Matius 6:33). Tiga hal penting yang terlihat dalam hidup para rasul yang menggambarkan hal ini secara nyata, ialah: a. Mereka menempatkan pelayanan rohani di atas segala-galanya, meskipun mereka ada terlibat juga dalam pelayanan sosial dan pelayanan fisik seperti terlihat dalam Kisah Para Rasul 6:1-4. b. Mereka menyatukan kehidupan berdoa dan berkhotbah secara seimbang (Kisah Para Rasul 6, 2, 4). c. Mereka menempatkan pelayanan penginjilan lebih utama dari semua pelayanan (Kisah Para Rasul 12:2,24).

Keenam, ia adalah hamba yang menerima dan menerapkan pelayanan bersama sebagai satu tim (Kisah Para Rasul 3:1,4;4: 23 - 31); doa bersama, daya bersama dan dana bersama.

Ketujuh, Ia adalah hamba yang yang memiliki berita Injil Keselamatan yang membara dalam desakan Tuhan yang menggelora di dalam dada hamba Allah menyebabkan ia tak tertahankan dalam proklamasi Injil keselamatan itu (Kisah 14:19 20).

Kedelapan, ia adalah hamba yang rela berkorban dan rela menderita bahkan mati sekalipun bagi pemberitaan Injil dalam Tuhan Yesus Kristus yang telah mati dan bangkit bagi dunia ini (Kisah 4:1231;7:60). Hal ini dilaksanakan dengan sukacita (Filipi 4:4-9).

Kesembilan, ia adalah hamba Allah yang menyampaikan Firman Allah (I Timotius 4:2a), bukan dari dongeng atau pengalaman dirinya. Artinya bukan suatu eisegese yaitu hasil pemikiran yang didukung dengan Firman Tuhan, melainkan

\footnotetext{
$\begin{array}{ccc}{ }^{26} \text { George W.Peters dalam Buku } & \text { Karya } \\ \text { Seminar } & \text { Pertumbuhan } & \text { Gereja }\end{array}$ ilmiah
}

apa yang dikatakan oleh Firman Tuhan itu sendiri. ${ }^{26}$

Dari apa yang disampaikan Peters, kita bisa lihat melihat unsur-unsur kredibilitas dari seorang ham-ba Allah dalam hal ini seorang gem-bala, yang hidupnya dapat dipakai Allah untuk mendatangkan per-tumbuhan gereja-Nya. Sangat jelas mereka adalah orang-orang yang terlebih dahulu telah menerima visi dan berjalan dalam visi yang Tuhan berikan. Selain itu mereka adalah orangorang yang memiliki karakter hamba seperti mau berkorban tanpa ambisi mencari kekayaan material dan kepentingan pribadi dan ini adalah sebuah bentuk lain dari integritas yaitu ketulusan hati. Mereka adalah orang-orang yang terus mengembangkan kompetensi mereka dalam hal menyampaikan firman Tuhan, artinya mereka terus mengembangkan cara mengkomu-nikasikan firman Tuhan kepada mereka yang belum percaya Kristus dan juga jemaat Tuhan. Mereka menyatukan kehidupan berdoa dan berkhotbah secara seimbang, artinya secara konsisten mereka membangun kehidupan doa sekaligus mengem-bangkan kotbahnya. George W. Peters juga menggambarkan dinami-ka pertumbuhan gereja dimana terlihat jelas bahwa ada kaitan yang sangat erat antara gereja yang bertumbuh dengan hadirnya seorang hamba Allah di dalamnya. Pemimpin gereja (gembala sidang atau gembala cabang) merupakan salah satu penentu dari perkembangan gereja yang dipimpinnya. Mau tidak mau, seorang pemimpin gereja harus dapat memiliki dan menjaga kredibilitas pribadinya.

\section{KESIMPULAN}

Pemimpin yang efektif menunjukkan kredibilitasnya. Kemu-dian kredibilitas pribadi seorang pe-mimpin yang mumpuni seharusnya akan mampu mengembangkan orga-nisasi atau

1989:Theologia $\quad$ Pertumbuhan $\quad$ Gereja
(Jakarta:Panitia SPG, 1989), 38-39.


perusahaan atau gereja yang dipimpinnya. Meningkatnya kredibilitas seorang pemimpin se-harusnya berbanding lurus dengan pengembangan organisasi atau perusahaan atau gereja yang dipim-pinnya. Untuk mengembangkan organisasi gereja, Peter Wagner me-nulis: "The pastor is the major key to the growth of the local church." 27 Kunci utamanya selalu ada di gem-bala sebagai pemimpin dari organisasi gereja tersebut. Tepatnya kredibilitas didalam diri gembala itu.

\section{DAFTAR PUSTAKA}

Barna, George. A Fish Out of Water. Nashville: Integrity Publisher, 2002. Leader on Leadership : Pandangan Para Pemimpin Tentang Kepemimpinan. Pen. Fabiola Hendrati. Malang : Gandum Mas, 2009.

Bons-Storm,Maria.Apakah

Penggembalaan Itu? Jakarta : BPK

Gunung Mulia, 2004

Engstrom, Ted W. The Making of Christian Leader . Grand Rapids, Michigan : Baker Book House, 1980

Glazier, Stephen. Random House Word Menu. Toronto : Random House of Canada Limited, 1992.

Hybels, Bill. Kepemimpinan yang Berani. Batam : Golden Press, 2004.

Iverson, Dick., Jack W. Hayford and Frank Damazio. Building Churches That Last. Oregon: City Bible Publishing, 2008

Kouzes, James M dan Barry Z. Posner. Credibility: How Leaders Gain and Lose it, Why People Demand it..San Fransisco : Josey-Bass, 2011

The Leadership Challenge (Tantangan Kepemimpinan). Ed. Ketiga. Terj. Revyani Sjahrial. Jakarta: Erlangga, 2004
Meyers, Rick. STRONG Dictionary ESWORD Bible, 2000-2016

Munroe, Myles. The Spirit of Leadership. Jakarta : Immanuel, 2006.

Munthe, A., Tema-Tema Perjanjian Baru. Jakarta : BPK Gunung Mulia, 2006.

Peters, George W. Teologi Pertumbuhan Gereja, Malang: Gandum Mas, 2002

The New Oxford Illustrated Dictionary. Sidney: By Books Inc. Oxford University Press, 1978

Wagner, Peter. Gereja Saudara Dapat Bertumbuh. Malang : Gandum Mas, 2002

Williams, Pat. Leadership Excellence. Ohio : Barbour Publishing, Inc., 2012.

\section{BIODATA PENULIS}

Johannes Rajagukguk lahir di Medan, 7 November 1972. Menem-puh pendidikan S1 di UNIKA Parah-yangan Bidang jurusan Teknik Arsitektur lulusan tahun 1996. Ke-mudian melanjutkan S2 Theology di STT Bethel Indonesia Petamburan lulus Tahun 2013. Ditahun 2012, me-nyelesaikan Certified Behavior Consultant Power Character dan melanjutkan kembali Certified Behavior Consultant Grade II lulus ditahun 2014. Tahun 2017 berhasil menye-lesaikan Doctor Theology di STT Bethel Indonesia Petamburan. Penulis saat ini adalah salah satu Dosen di STTBI Petamburan, The New STTB The Way Tanjung Barat dan STTB Bekasi. Penulis juga seorang Gembala di GBI Hall of Joy Kramat Jati dari tahun 2009 sampai sekarang. Penulis juga anggota inti dari Departemen Pengajaran GBI Gatot Subroto dan pengajar aktif Kehidupan Orientasi Melayani (Kelas Pendalaman Alkitab) di GBI Gatot Subroto sampai saat ini. 